\title{
BEHAVIOR OF COMPRESSION-LOADED COMPOSITE PANELS WITH STRINGER TERMINATIONS AND IMPACT DAMAGE
}

\author{
Dawn C. Jegley \\ NASA Langley Research Center \\ Hampton, VA \\ Presented at the AIAA/ASME/ASCE/AHS 39th Structures, \\ Structural Dynamics, and Materials Conference
}

AIAA Paper No. 98-1785-CP

Long Beach, California 


\title{
BEHAVIOR OF COMPRESSION-LOADED COMPOSITE PANELS WITH STRINGER TERMINATIONS AND IMPACT DAMAGE
}

98-1785

\author{
Dawn C. Jegley* \\ NASA Langley Research Center \\ Hampton, VA
}

\begin{abstract}
$\underline{\text { Abstract }}$
The results of an analytical and experimental study of graphite-epoxy stiffened panels with impact-damaged stringer terminations are presented. Five stitched graphite-epoxy panels with stiffeners with a gradual reduction in either thickness or height were examined. Panels were analyzed using finite element analysis and tested by loading them in axial compression to a predetermined load. The panels were then subjected to impact damage and loaded to failure. Axial midplane strains, surface strains, interlaminar strains and failure results are discussed.
\end{abstract}

\section{Introduction}

One of the goals of the NASA Advanced Composites Technology Program (ACT) was to develop the technology needed for future low-cost, light-weight composite structures for commercial transport aircraft. One material system which has the potential of reducing the weight and cost of commercial transport aircraft structure is a stitched graphite-epoxy material system. By using stitches through the thickness of a low-cost graphite-epoxy material system, the labor associated with wing cover panel fabrication and assembly can be significantly reduced. When the entire wing cover panel is stitched together, including stringers, intercostals and spar caps, the need for mechanical fasteners is almost eliminated, which significantly reduces part count, and, therefore, cost. However, in order to take advantage of this material system, problems associated with impact damage must be understood and resolved. Damage tolerance characteristics can be improved by using advanced resin systems, but the currently available resins which provide improved damage tolerance are prohibitively

\footnotetext{
*Senior Aerospace Engineer, Structural Mechanics Branch. Senior Member, AIAA.

Copyright (C) 1998 by the American Institute of Aeronautics and Astronautics, Inc. No copyright is asserted in the United States under Title 17, U.S. Code. The U.S. Government has a royalty-free license to exercise all rights under the copyright claimed herein for Governmental Purposes. All other rights are reserved by the copyright owner.
}

expensive for use in low-cost commercial aircraft. Panels fabricated with low-cost resins usually have degraded strength capability when subjected to lowspeed impact damage, such as hail damage. By using stitches through the thickness of a low-cost graphiteepoxy material system, damage propagation is reduced, and improved damage tolerance is possible. One critical consideration for evaluating the effect of impact damage on a graphite-epoxy wing is the effect of impact damage in stiffener termination regions which have significant local stress gradients.

To evaluate the effect of impact damage on the response of composite panels with stiffener terminations, five panels were cut from the undamaged regions of a 12-foot-long, stitched graphite-epoxy wing box. This wing box was fabricated by the McDonnell Douglas Aerospace Company as part of the NASA Advanced Composites Technology Program and was loaded to failure at the NASA Langley Research Center. A complete description of the wing box is presented in reference 1. Panels used in this study have stringers with a gradual reduction or taper in either thickness or height. The panels were analyzed using finite element analysis methods and were tested by loading the panels in axial compression to a predetermined load. The panels were then subjected to impact damage and loaded to failure to determine their residual strength.

\section{Panel Description}

Two single-stringer panels and three multi-stringer panels were cut from the McDonnell Douglas wing box. All panels were fabricated from Hercules, Inc. AS4/3501-6 and IM7/3501-6 graphite-epoxy materials which were stitched together using E. I. DuPont de Nemours, Inc. Kevlar ${ }^{\circledR}$ thread. IM7 graphite fibers were only used for the 0 degree fibers in the skin of the multi-stringer panels. The composite skin and stiffeners were composed of layers of the graphite material forms that were prekitted in nine-ply stacks. Each nine-ply stack had a $\left[45 /-45 / 0_{2} / 90 / 02 /-45 / 45\right]_{\mathrm{T}}$ laminate stacking sequence and was approximately 0.058 inches thick. Several nine-ply stacks of the prekitted material were used to build up the desired thickness at each location. The composite wing box was fabricated using the Resin Film Infusion (RFI) process which is described in reference 2. 
Single-stringer panels with centrally located stringers were cut from the upper cover panel of the wing box and are designated as panels U-1 and U-2 herein. Panel U-1 is shown in figure 1. Multi-stringer panels were cut from the lower cover panel of the wing box and are designated as L-1, L-2 and L-3 herein. Panel L-2 is shown in figure 2.

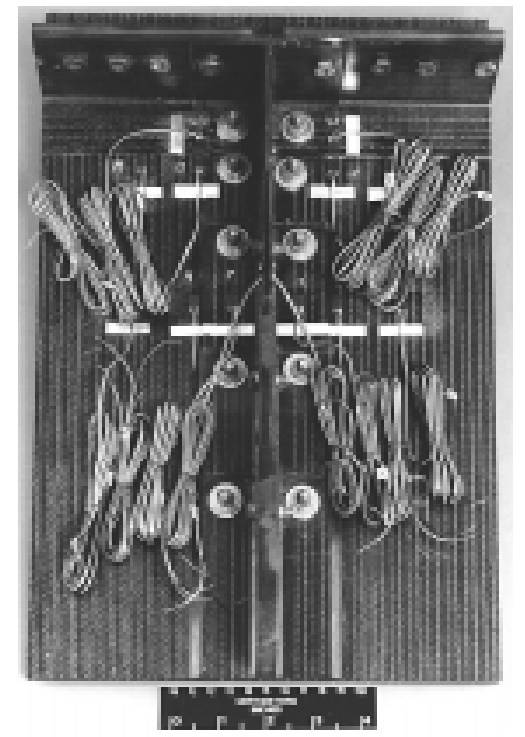

Figure 1. Photograph of single-stringer panel U-1 prior to testing.

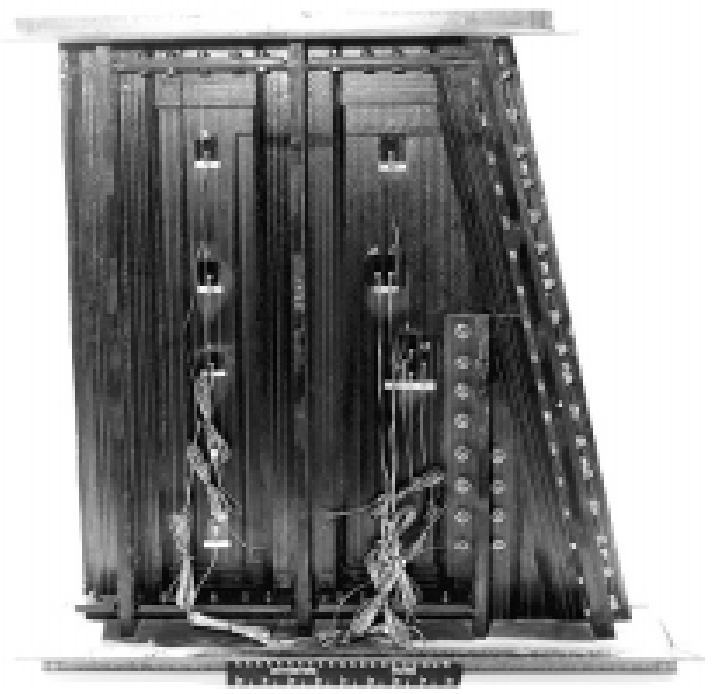

Figure 2. Photograph of multi-stringer panel L-2 prior to testing.

The stringers and intercostals are blade stiffeners which are approximately 2.3 inches tall in the singlestringer panels and are 2.0 inches tall in the multistringer panels. All stringer blades in the panels are nominally 0.46 inches thick (eight stacks) with a 1.12- inch-wide flange on either side of the web. All intercostal blades are nominally 0.116 inches thick (two stacks) with a 1.1-inch-wide flange on either side of the web. The flange thickness is half the blade thickness. Intercostals are perpendicular to the stringers. A graphite-epoxy rib was bolted to each intercostal in the original wing box. This rib was cut to match the height of the intercostal for these singleand multi-stringer panels rather than risking damaging the intercostals by removing the bolts. Because of concerns that the stiffener termination region or runout region would fail prematurely in the wing box test, a row of bolts was added to each flange of a terminating stringer to prevent the stringer flange from separating from the skin.

The geometry of the single-stringer panels is shown in figure 3 . For the single-stringer panels the stringer blade is eight stacks thick at the thicker end and two stacks thick at the termination point or thinner end. Stacks are terminated on both sides of the blade at three inch intervals. Stringer flanges are always half the thickness of the blade. The stringer blade terminates at the intercostal by folding out into tabs that are placed against the intercostal blade as shown in figure 3. Additional bolts were added to the stringer blade to prevent the blade from delaminating prematurely in the wing box test. The single-stringer panels are 15.25 inches long and 10.0 inches wide with the intercostal located two inches from one end of the panel. The only difference between the two singlestringer panels is that the entire skin of panel U-1 is five stacks thick while the skin of panel U-2 is five stacks thick over approximately half the width of the panel and six stacks thick for the rest of the panel.

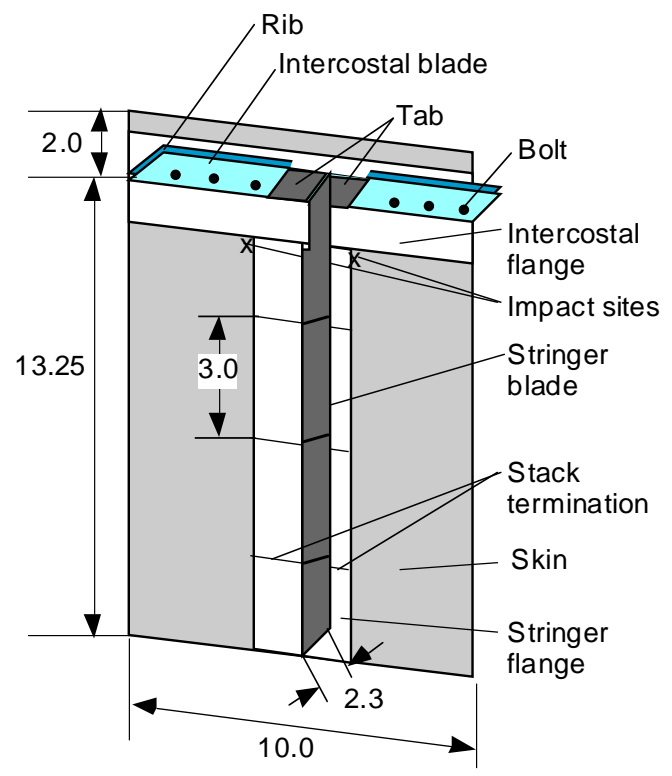

Figure 3. Geometry of a single-stringer panel. Length dimensions are in inches. 
The geometry of the multi-stringer panels is shown in figure 4 . The multi-stringer panel skins range in thickness from six to eight stacks. Each multi-stringer panel has two 8-stack-thick stringers along the full length of the panel and one 8-stack-thick stringer which tapers from the full stringer height of 2.0 to 0.0 inches over a distance of 7.5 inches.

Stringer flanges remain four stacks thick for the entire stringer length. The spar cap, which is the same height as the stringers, runs the length of the panel and is oriented at an angle of 13 degrees to the stringers. In the original wing box, graphite-epoxy ribs and spars were bolted to the intercostals and spar caps, respectively. For the multi-stringer panels the rib and spar were cut to the same height as the intercostals. Intercostals were located two inches from the bottom of panel L-1, and two inches from the bottom and top of the panel L-2. Panel L-3 has no intercostals. The tapered stringer terminated at the flange of the spar cap, as shown in figure 4 . The multi-stringer panels are between 21 and 25 inches long and 21.8 inches wide at one end. The other end is between 16.25 inches and 17.25 inches wide.

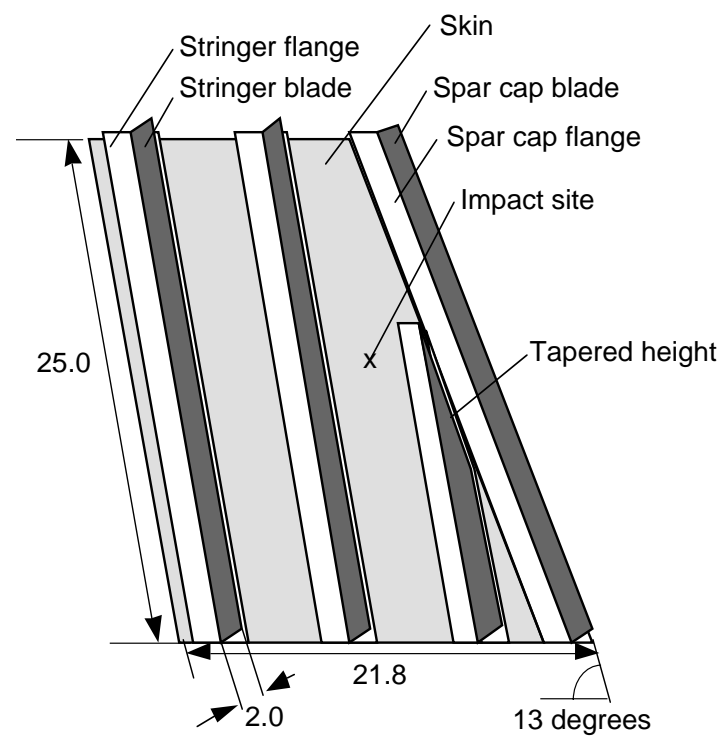

Figure 4. Geometry of a multi-stringer panel without intercostals. Length dimensions are in inches.

The loaded edges of all specimens were potted in an epoxy compound that was one inch deep to simulate clamped end conditions. These ends were ground flat and parallel prior to testing.

\section{Impact Damage}

Damage was inflicted on the unstiffened side of the panels using two methods. The first method of inflicting damage was to drop a 25-lb weight with a 1inch-diameter tup a specified distance to inflict a desired level of damage. The second method was to place the panel in a test machine and then to apply a compressive static load to indent the panel at a specified point with a 1-inch-diameter tup until the desired level of damage was reached. The level of damage was defined by either a $100 \mathrm{ft}-\mathrm{lb}$ impact energy or by the amount of permanent indentation or dent depth. A dent which is more than 0.1 inches deep is assumed to be visible. Damage size was also measured using an ultrasonic Cscan procedure. The level of damage, method of inflicting damage and damage size are listed in Table 1 for each panel. Panel U-1 was not damaged and panel U-2 was damaged at two locations. The other three panels were each impacted at one location.

Photographs of damage sites for two panels prior to final compressive loading are shown in figure 5. White dots in figure 5(b) outline the damage region as determined by the $\mathrm{C}$-scan procedure.

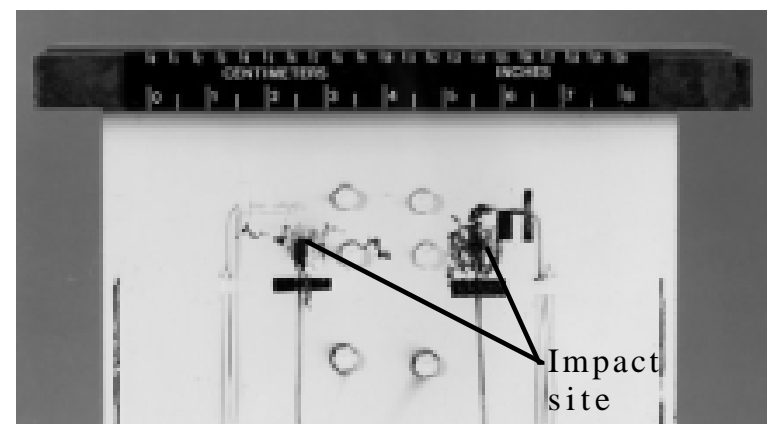

(a) Panel U-2

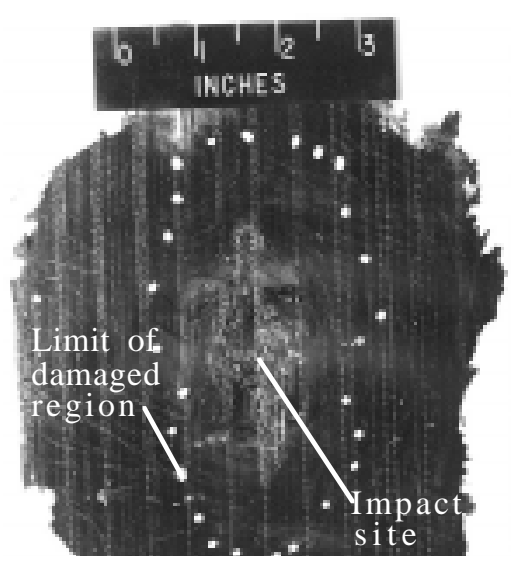

(b) Panel L-1

Figure 5. Typical impact damage.

All multi-stringer panels have a thick layer of resin on the unstiffened surface. Indentation depth for these panels is based on a measured indention at the impact site, less the thickness of the surface resin layer. The thickness of the surface resin was determined by measuring the thickness removed where fasteners were added at the adjacent tapered stiffener during assembly of 
the wing box. Extra surface resin thicknesses on the multi-stringer panels ranged from 0.02 inches to 0.07 inches.

\section{Loading and Instrumentation}

All panels were loaded in axial compression. Knife edge supports were used on the unloaded edges of panels U-1 and U-2 to minimize out-of-plane motion of the skin. No support was provided for the intercostal or intercostal flange. No edge supports were used for testing the multi-stringer panels. Panels were loaded to a predetermined load level, load was removed, and then the panels were impact damaged. Panels were then loaded to failure. Panels were instrumented with strain gages near to and away from the impact sites. DCDTs (Direct Current Displacement Transducers) were used to monitor end-shortening and out-of-plane displacements.

Load rates were approximately $10,000 \mathrm{lb} / \mathrm{min}$ for the single-stringer panels and $80,000 \mathrm{lb} / \mathrm{min}$ for the multi-stringer panels.

\section{$\underline{\text { Analysis }}$}

A geometrically nonlinear analysis of each panel was conducted with the finite element code STAGS (ref. 3). A unique model was created for each panel so that all differences in skin thickness and geometry could be considered. The models used for panels U-1 and L-1 are shown in figure 6. Similar models were used for the other panels tested.

Material properties used in the analysis are shown in Table 2. Intercostals and ribs were included in the models where appropriate, however, fasteners through the skin were not included in any of the finite element models.

Stringer and intercostal flanges were modeled separately from the skin for all finite element models, and eccentricities were used to offset elements with thicker skin to account for changes in skin thickness so the models would accurately reflect these details.

\section{Results}

Experimental and analytical results for the study of two single-stringer panels and three multi-stringer panels are presented in this section, and panel failure results are summarized in Table 3 . In comparisons between experimental and analytical results, experimental results are shown as solid lines and analytical results are shown as dashed lines in all plots.

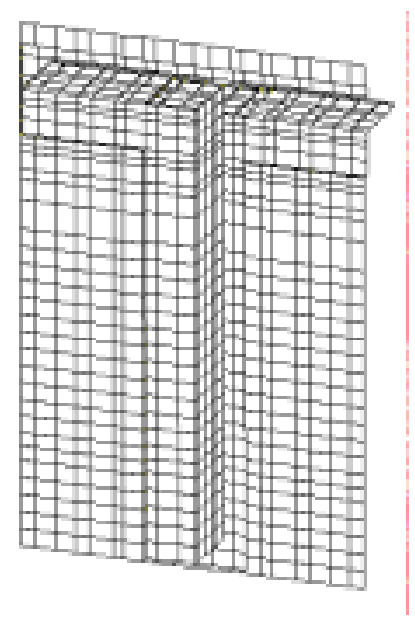

(a) Single-stringer panel

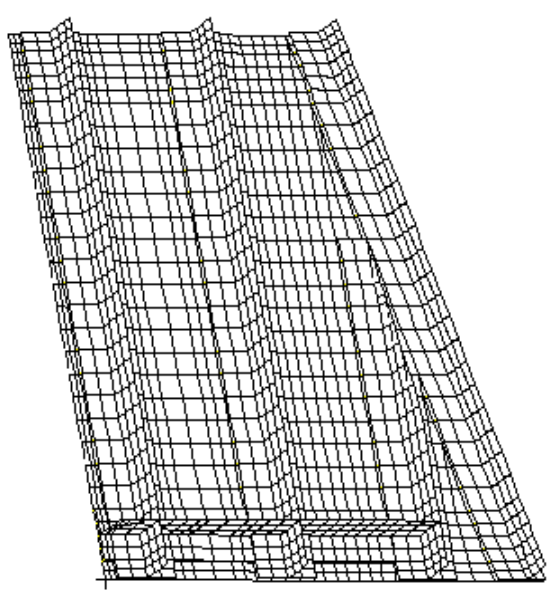

(b) Multi-stringer panel

Figure 6. Finite element models.

\section{$\underline{\text { Single-stringer panels }}$}

Two single-stringer panels, identified herein as U-1 and U-2 were loaded to failure. Panel U-1 was not impact damaged.

The axial surface strains in the skin of panel U-1 at a distance 4.75 inches away from the intercostal are shown in figure 7. Results from back-to-back strain gages agree well with each other, indicating little bending away from the intercostal. The axial strains in the skin at the edge of the intercostal flange are shown in figure 8. Experimental and analytical results indicate that bending behavior occurs in the region of the intercostal flange. Analytical and experimental results are in good agreement. 


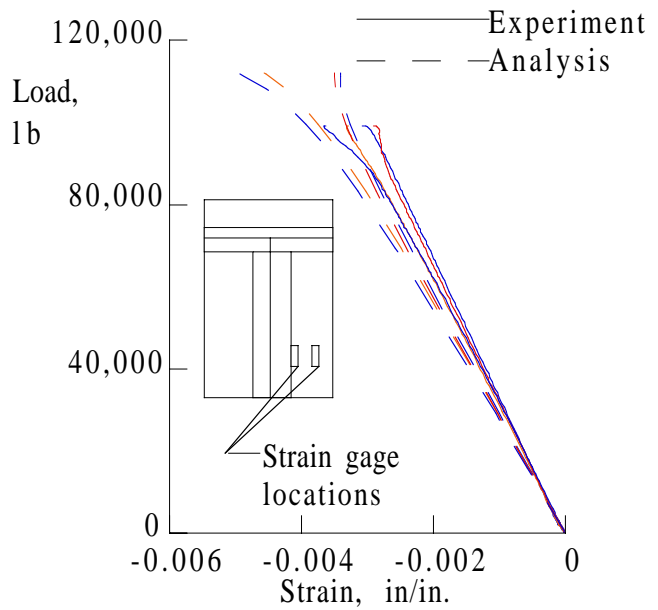

Figure 7. Axial far field strain in the skin of panel U-1.

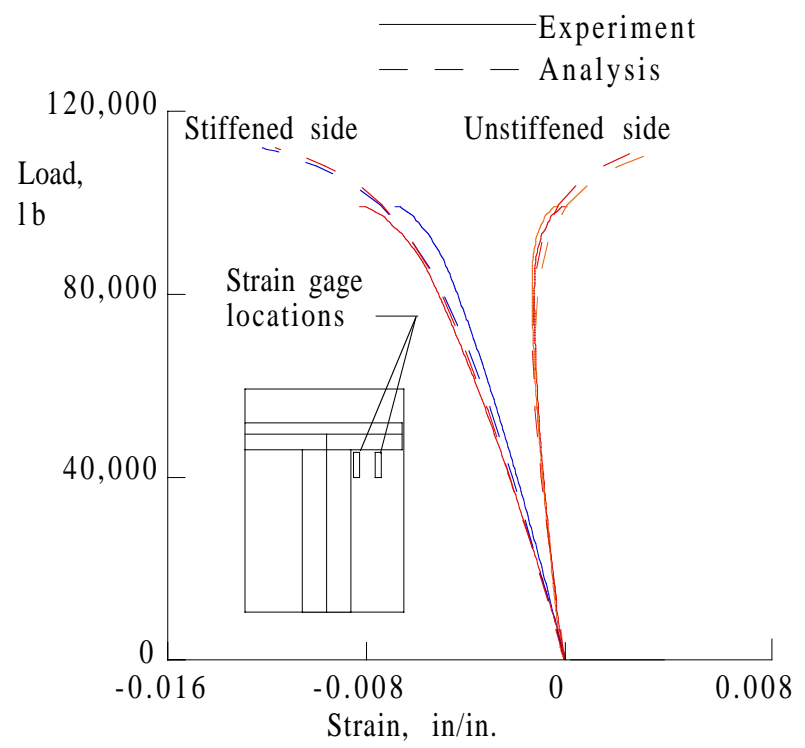

Figure 8. Axial strain in skin near the intercostal flanges for panel U-1.

Analytically determined axial surface strains for a load of $100,000 \mathrm{lb}$ are shown in figure 9. The maximum compressive axial surface strain occurs in the intercostal flange near the intercostal, but the maximum axial strain at the laminate midplane occurs in the stringer flange near the intercostal. Based on an allowable axial strain value at the laminate midplane for undamaged structure of .0093 in/in., failure should not occur due to axial strain for a load less than $108,500 \mathrm{lb}$. Lateral strains were small enough to have little effect on failure. However, the shear strain in the intercostal flange is predicted to exceed the shear strain allowable of $.0126 \mathrm{in} / \mathrm{in}$. for loads greater than 91,200 lb. Shear strain in the intercostal flange causes or contributes to failure of the panel since the panel failed at $98,200 \mathrm{lb}$.

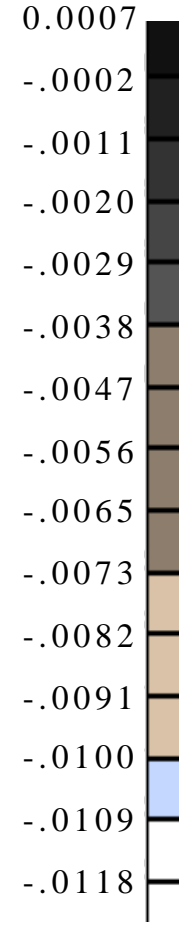

Figure 9. Axial surface strain for a load of $100,000 \mathrm{lb}$ for panel U-1.

The predicted interlaminar stresses, normalized by material failure stresses, can be combined to evaluate interlaminar stresses between flanges and skin. The assumed interlaminar tensile normal stress at failure, $\mathrm{F}_{\mathrm{Z}}=5.9 \mathrm{ksi}$, and the assumed interlaminar shear stress at failure, $F_{S}=13.5 \mathrm{ksi}$, are used to obtain an interlaminar failure parameter. A normalized interlaminar failure prediction is obtained by using the equation:

$\mathrm{I}=\left(\left(\sigma_{\mathrm{Z}} / \mathrm{F}_{\mathrm{Z}}\right)^{2}+\left(\tau_{\mathrm{xZ}} / \mathrm{F}_{\mathrm{S}}\right)^{2}+\left(\tau_{\mathrm{yz}} / \mathrm{F}_{\mathrm{S}}\right)^{2}\right)^{1 / 2}$

where $\sigma_{\mathrm{Z}}$ is the normal stress and $\tau_{\mathrm{xz}}$ and $\tau_{\mathrm{yz}}$ are the interlaminar shear stresses. Based on this normalization, any value of the interlaminar failure parameter greater than 1.0 could signify that failure occurs at the corresponding location. The values of the interlaminar failure parameter is shown in figure 10 for the interface between the skin and the stringer flange.

The maximum interlaminar stress in the stringer flange occurs at the end of the flange where it terminates at the intercostal flange. At this location the interlaminar failure parameter is approximately equal to 2.0 for a load of $100,000 \mathrm{lb}$. The maximum axial strain, shear strain and interlaminar shear strain occur in close proximity, and failure could result from a combination of strains. 

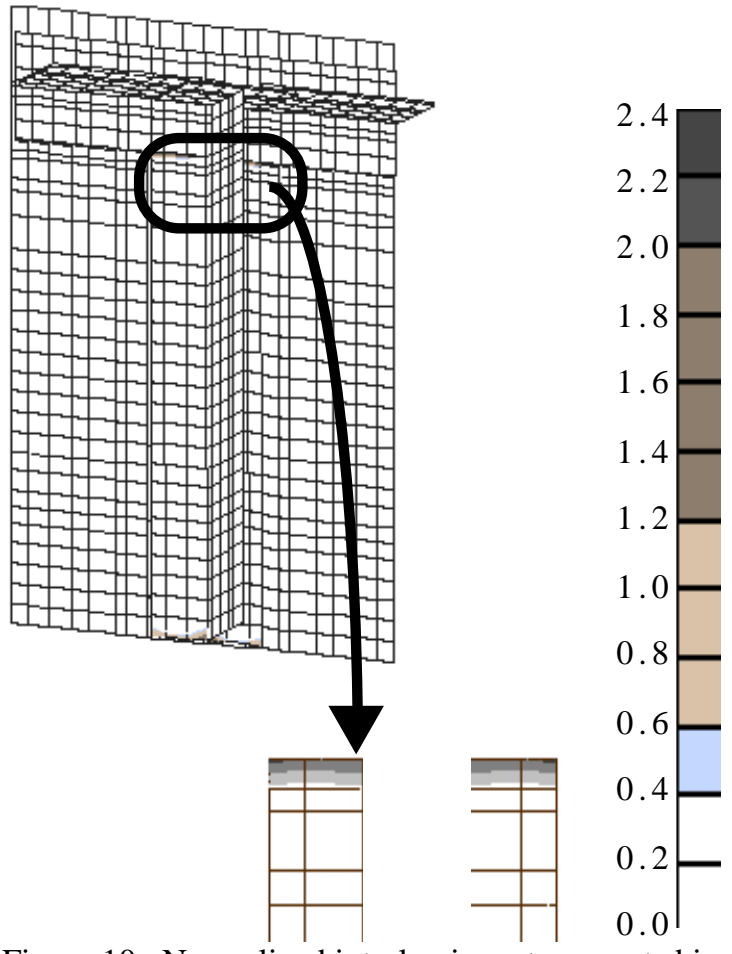

Figure 10. Normalized interlaminar stresses at skin-tostringer flange interface for a load of $100,000 \mathrm{lb}$ for panel U-1.

Test results indicate that failure initiates at the interface between the skin and stringer flange. The separation of the stringer flange from the skin occurs immediately beneath the blade of the stringer. The analytical prediction of the location of failure agrees with the experimental results. The panel failed at $98,200 \mathrm{lb}$ of load.

Panel U-2 was initially loaded to $83,000 \mathrm{lb}$. The panel was not damaged during the initial loading. The panel was unloaded and subjected to a dropped-weight impact and a static indentation which resulted in two damage sites, each with dent depths of approximately 0.15 inches. The resulting damage was clearly visible. Descriptions of the damage are presented in Table 1 and a photograph of the damage is shown in figure 5 .

Results for end-shortening and out-of-plane displacements for panel U-2 during the preliminary (undamaged) loading and as predicted by finite element analysis are shown in figure 11. Out-of-plane displacements were measured 5.5 inches from the bottom of the panel near the knife edge support and 10.6 inches from the bottom of the panel in three locations across the width of the panel. Analytical and experimental results are in good agreement.

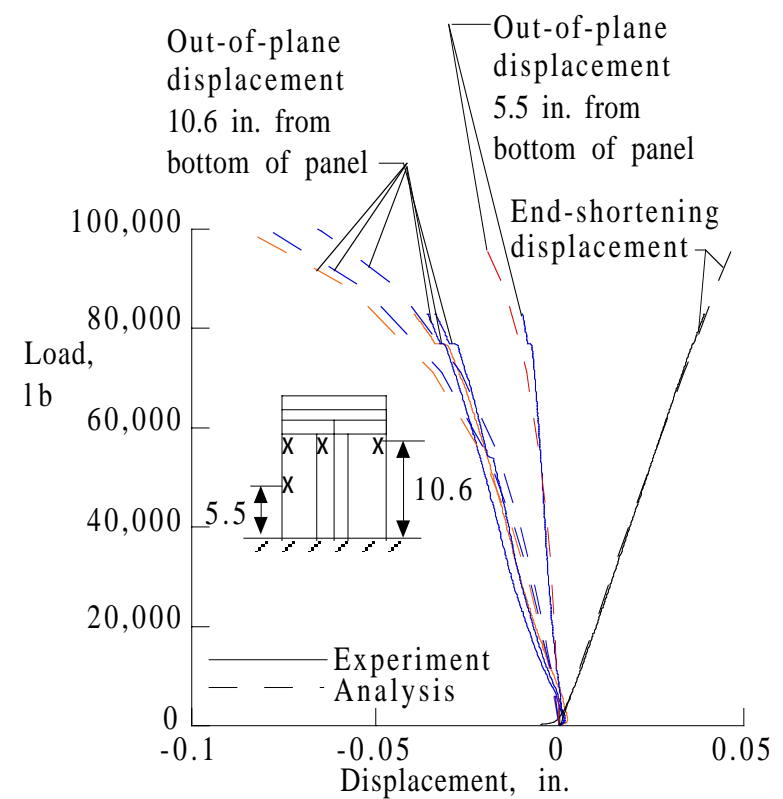

Figure 11. Displacement results for undamaged panel U-2. All dimensions are in inches. An "x" on the figure represents the location of out-of-plane displacement measurement.

After being subjected to impact damage, the panel was loaded to failure. The impact damage had little effect on the far-field behavior or on the global behavior of the panel. The local effect of the impact damage can be seen in figure 12, in which results are shown for strain gages within one inch of the impact sites. Surface damage closer than one inch from the impact site was too severe to allow strain measurements.

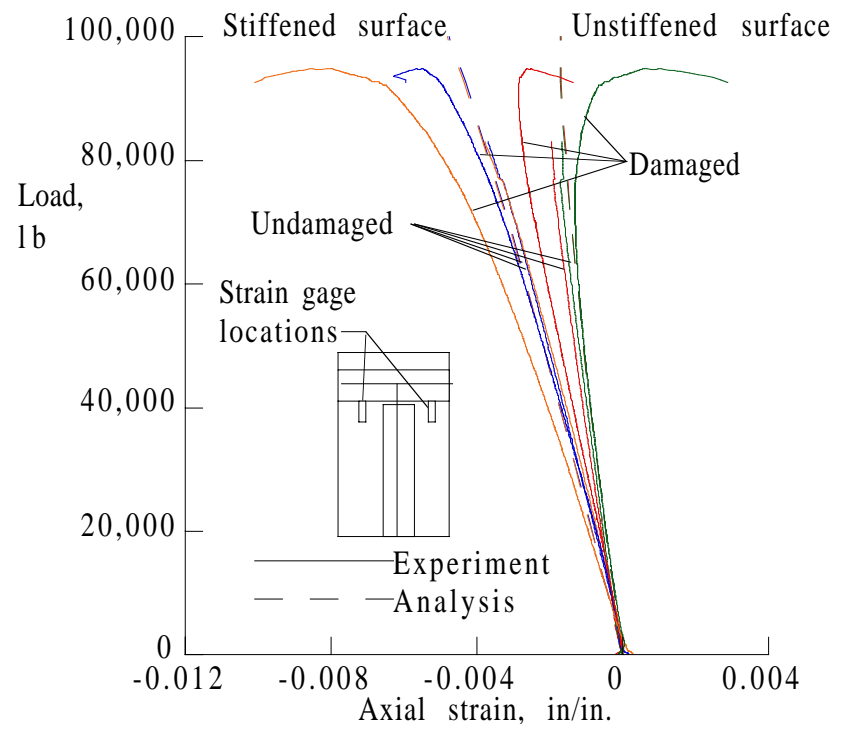

Figure 12. Axial strains near the intercostal flange in panel U-2. 
The allowable midplane strain for damaged structure is $.0053 \mathrm{in} / \mathrm{in}$. The analysis predicts a strain at the impact site of $.0053 \mathrm{in} / \mathrm{in}$. for a load of 147,000 $\mathrm{lb}$. Failure through the impact site would not be expected for loads less than $147,000 \mathrm{lb}$. Since the failure load is significantly less than $147,000 \mathrm{lb}$, the midplane strain at the impact site cannot be used to predict failure of this panel.

Ideally, a panel with a 0.1-inch-deep indentation (caused by impact damage) will not fail when subjected to a load that causes a stress less than the design stress at the reference surface of the skin at the indentation site. The design stress is determined by the skin thickness. Based on a design stress of $37.5 \mathrm{ksi}$ for the 5 -stack-thick region of the panel, a failure load greater than $120,000 \mathrm{lb}$ would be expected. The panel failed with a stress of $29.4 \mathrm{ksi}$ at the impact site, which is approximately 21 percent less than the design stress. However, the panel was damaged with dents 50 percent deeper than the 0.1-inch-deep dent-depth criterion. In addition, the loading conditions for the panels are not the same as for the wing box, so any comparison between the behavior of the compression-loaded panels and the compressed, bent, and twisted wing upper cover panel must take these differences into account.

A method to predict failure in damaged, stitched graphite-epoxy structure by examining predicted bending and membrane strains a small distance away from the impact site is described in reference 4 . This method calculates a, so called, "PDF" parameter which leads to a predicted failure load. A failure prediction for the damaged single-stringer panel based on this method results in a failure prediction of $95,550 \mathrm{lb}$. After being subjected to impact damage, the panel was loaded to failure. The panel failed at $94,600 \mathrm{lb}$ of load, or 99 percent of the failure load predicted using the method of reference 4 . In the single-stringer panel, the bending behavior in the region of the impact site significantly influences the failure of the damaged panel.

In single-stringer panels, the interlaminar strain between the stringer flange and the skin and the shear strain in the intercostal flange caused the failure in the undamaged panel. The axial strain near the impact site, and the shear strain in the stringer flange caused the failure to occur in the damaged panel.

\section{Multi-stringer Panels}

Three multi-stringer panels, identified herein as L-1, L-2 and L-3, were loaded to failure. Each panel was loaded to a pre-determined load, unloaded, damaged using a dropped-weight impactor and then loaded to failure. Damage resulted in permanent indentation depths ranging from less than 0.01 to 0.16 inches. Impact sites were on the skin near the flange of the tapered stringer away from the spar cap. This location was a point of high strain, but not the point of maximum strain. The point of maximum strain in the skin was in the skin near the tapered stringer and spar cap. A description of the inflicted damage is given in Table 1. Preliminary load levels were determined by predicting the load level which would induce the design stress at the planned damage site.

Panel L-1 was initially loaded to approximately $485,000 \mathrm{lb}$. No damage was found that was caused by the initial loading. Axial surface strains predicted by finite element analysis and measured during the preliminary and final loading are shown in figures 13 and 14. Impact damage had little effect on the far field strains, but had a significant effect on strain gage results 0.5 inches away from the impact site.

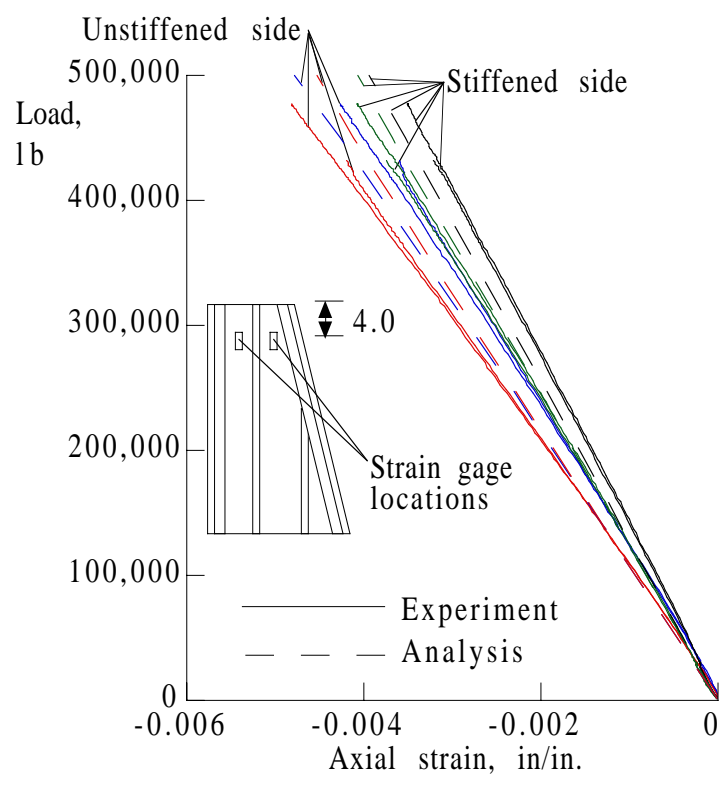

Figure 13. Axial strains in the skin away from the impact site of panel L-1.

Analysis indicates that the maximum axial strain anywhere in the panel is at the free edge of the spar cap blade, and that the axial strain allowable would be exceeded for loads greater than approximately 706,000 $\mathrm{lb}$. The allowable shear strain would not be exceeded for loads less than 900,000 lb. Interlaminar shear and normal strains between the panel skin and stringer flanges do not exceed the allowable strains for loads less than the failure load, and have little effect on failure.

Panel L-1 was subjected to severe impact damage resulting in an indentation with a depth of 0.16 inches. The criterion of allowable strain at the reference surface of .0053 in/in. and the criterion described in reference 4 
assume an indentation depth of approximately 0.1 inches. Damage to the panel is significantly more severe than appropriate for either of these methods. However, the predicted strain at the impact site exceeds the allowable axial strain for damaged structure with loads greater than $650,000 \mathrm{lb}$. By using the method described in reference 4 , panel L-1 would be expected to fail at a load of $640,000 \mathrm{lb}$. The two methods produce similar results since there is little bending behavior near the impact site.

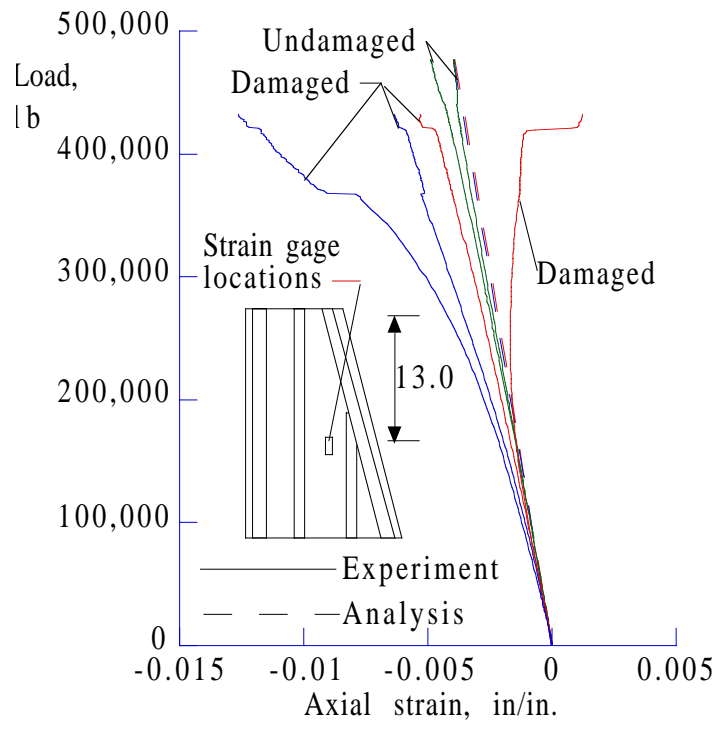

Figure 14. Axial strains in the skin at the impact site of panel L-1.

Panel L-1 failed through the impact site and the point of maximum strain in an undamaged skin with a load of 435,000 lb, and with damage 1.6 times as severe as required by the criterion. The panel failed with a stress at the impact site of $35.2 \mathrm{ksi}$, which is approximately 89 percent of the design stress. An undamaged panel would have had a strain of approximately $.0037 \mathrm{in} / \mathrm{in}$. at the impact site for the load at which the damaged panel failed. The maximum midplane strain (based on the measured surface strains) near the impact site was equal to $.0052 \mathrm{in} / \mathrm{in}$. The predicted maximum strain in the panel away from the impact site is equal to .0043 in/in., which is significantly less than the allowable strain in undamaged structure. These results indicate that failure was caused by the strain in the region of the impact site. A photograph of panel L-1 after failure is shown in figure 15.

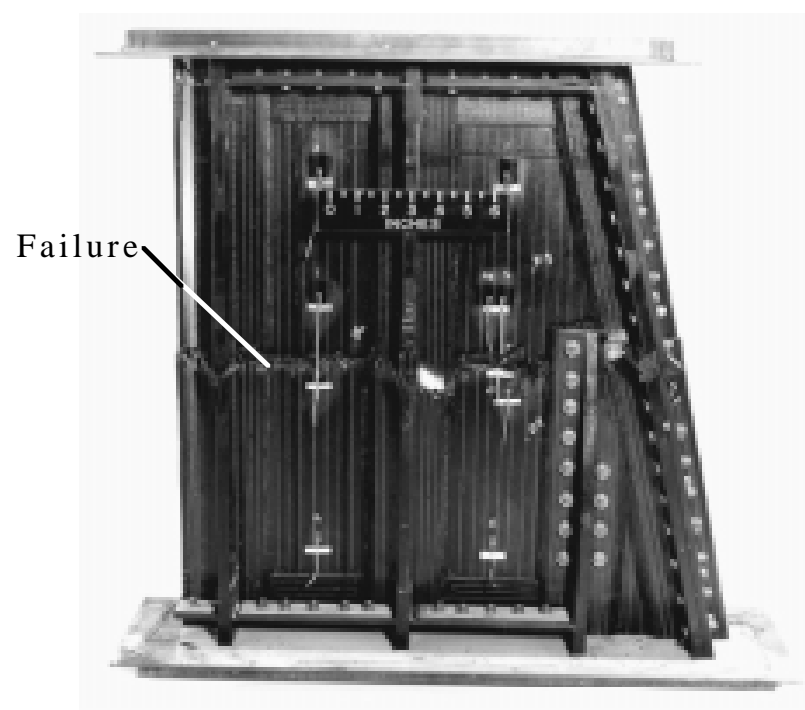

Figure 15. Failed panel L-1.

Panel L-2 was initially loaded to $447,000 \mathrm{lb}$. The panel was not damaged during the initial loading. Axial surface strains predicted by finite element analysis and measured during the preliminary and final loading are shown in figures 16 and 17. Strains located midbay and four inches from the top of the panel (away from the tapered stringer and impact site) are shown in figure 16. Strains near the impact site are shown in figure 17 . These strain results are for the loading prior to inflicting damage, for the damaged panel and for the analysis. Analysis accurately predicts far field strains and strains at the impact site. Impact damage has a significant effect on the strain within one inch of the impact site, but has no effect away from the impact site.

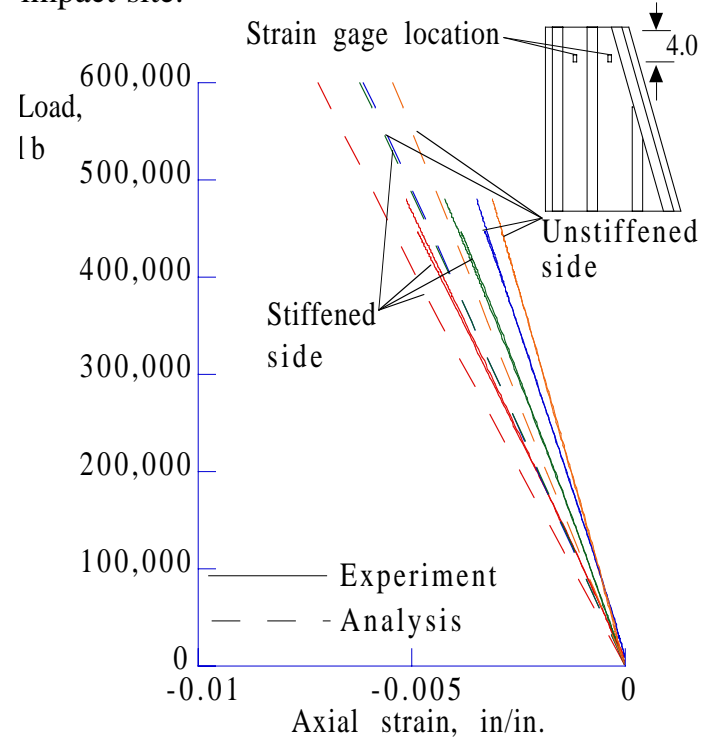

Figure 16. Axial surface strains in the skin away from the impact site of panel L-2. 


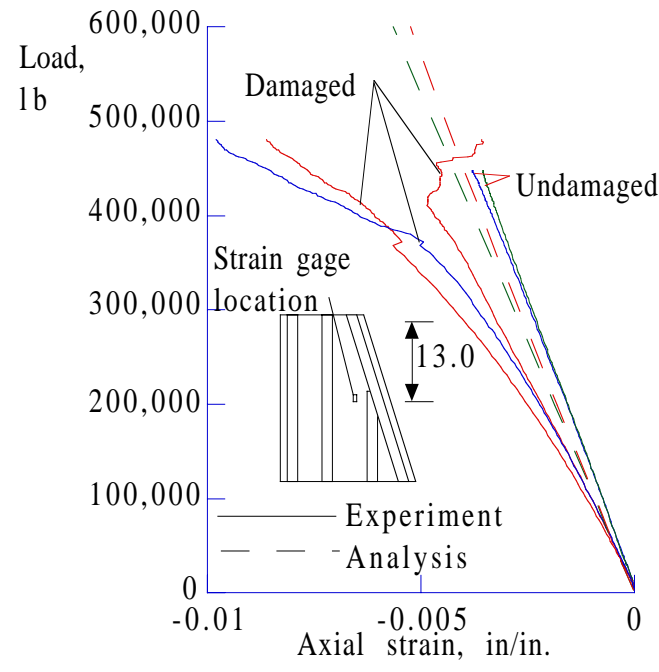

Figure 17. Axial surface strains in the skin at the impact site of panel L-2.

According to the finite element analysis, the maximum axial strain in panel L-2 occurs in the spar cap blade and does not exceed the allowable axial strain for loads less than approximately $650,000 \mathrm{lb}$. The allowable shear strain is not exceeded for loads less than $900,000 \mathrm{lb}$. Interlaminar shear and normal strains between the panel skin and stringer flanges do not exceed allowable values for loads less than the failure load and have little effect on failure.

The panel was subjected to impact damage resulting in an indentation with a depth of 0.11 inches. The allowable strain of .0053 in/in. at the impact site is exceeded for loads greater than $580,000 \mathrm{lb}$. Applying the method of reference 4 results in a predicted failure load of $570,000 \mathrm{lb}$. The panel failed through the impact site for a load that is approximately 85 percent of that predicted by analysis. The panel failed with a stress at the impact site of $44.6 \mathrm{ksi}$, which is 113 percent of the design stress.

Test data indicate that the load at which the maximum midplane strain (based on the surface strain gages) near the impact site reached $.0053 \mathrm{in} / \mathrm{in}$. was $397,000 \mathrm{lb}$. The panel failed at a load of 484,000 lb. The maximum midplane strain in the region of the impact site was .0062 in/in., which is 1.16 times the allowable strain value. The predicted maximum strain in the panel away from the impact site is .0058 in/in., which is significantly less than the allowable strain value in undamaged structure, so failure was caused by the strain in the region of the impact.

Panel L-3 was initially loaded to approximately $400,000 \mathrm{lb}$. The panel was not damaged during the initial loading. The panel was unloaded and damage was inflicted with $100 \mathrm{ft}-\mathrm{lb}$ of impact energy to the skin next to the tapered stiffener, but on the unstiffened side of the panel. Axial strains predicted by finite element analysis and measured during the preliminary and final loading are shown in figure 18 for strains at the impact site. Impact damage has little effect on strain at the impact site or far from the impact site. The relatively mild impact of $100 \mathrm{ft}-\mathrm{lb}$ did not disable the strain gage on the stiffened side of the panel at the impact site. Analysis accurately predicts the far field strains and strains at the impact site.

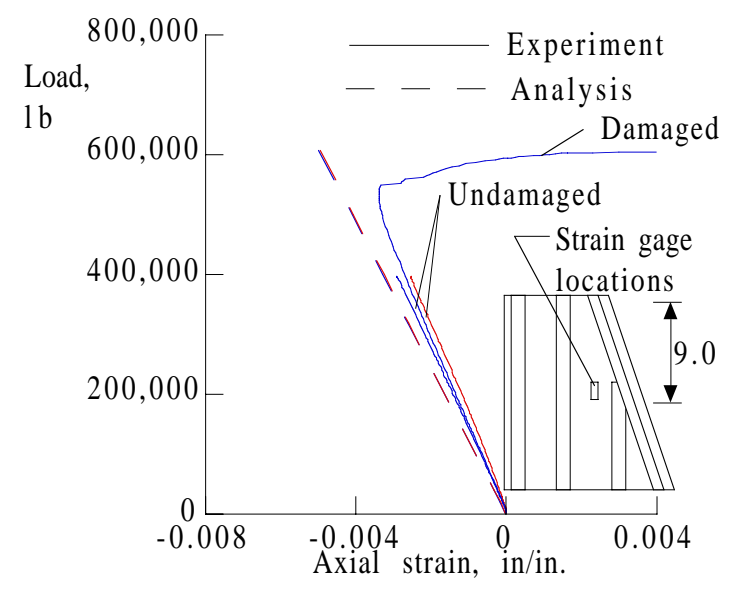

Figure 18. Axial surface strains in the skin at the impact site of panel L-3.

Analytically, a damage allowable strain value of $.0053 \mathrm{in} / \mathrm{in}$. at the reference surface of the skin at the impact site corresponds to a load of 648,000 lb. Applying the method described in reference 4 results in a predicted failure of $640,000 \mathrm{lb}$. The actual failure occurred through the impact site at $611,000 \mathrm{lb}$. Damage to the resin layer on the surface prevented strain from being measured at the impact site. The reference surface strain near the impact site was approximately $.005 \mathrm{in} / \mathrm{in}$. The panel failed at a strain that is slightly less than the allowable strain at the impact site. Failure prediction based on the damage allowable strain value and the analysis indicates that the panel failed at 95 percent of the prediction based on the method of reference 4 for impact damaged structure. However, that prediction is based on the assumption of a 0.1-inch-deep dent, rather than a dent depth of less than .01 inches that was applied to panel L-3. The predicted maximum strain in the panel away from the impact site is equal to $.0067 \mathrm{in} / \mathrm{in}$., which is significantly less than the allowable strain value in undamaged structure, so failure was caused by the strain in the region of the impact. The panel failed with a stress of $50.0 \mathrm{ksi}$ at the impact site, which is 115 percent of the design stress.

Interlaminar shear and normal strains between the panel skin and stringer flanges do not exceed allowable 
strain values for loads less than the failure load and have little effect on failure.

\section{Concluding Remarks}

Stitched graphite-epoxy panels were loaded to failure to evaluate the effect of impact damage in panels with a terminated stringer. The terminated stringer can be ended by a reduction in blade thickness or by a reduction in blade height. Panels with a single stringer whose blade contained a gradual reduction in thickness had high shear stress in the stringer flange and high interlaminar shear stresses between the stringer flange and skin. The maximum interlaminar stress in the stringer flange occurs at the end of the flange where it terminates at the intercostal flange. The maximum axial strain, shear strain and interlaminar strain occur in close proximity, and failure could result from any or a combination of these strains.

Test results for the undamaged single-stringer panel show that failure initiates at the interface between the skin and stringer flange. The separation of the stringer flange from the skin occurs immediately beneath the blade of the stringer. The location of failure predicted by analysis is the same as the panel failure location. The damaged single-stringer panel failed through the impact sites at 99 percent of the predicted failure load based on predicted membrane and bending strains in the region of the impact site. Significant bending behavior occurs in the single-stringer panels, and they failed with less stress in the skin than the design stress. The damaged single-stringer panel failed at a stress level that is 10 percent less that the failure stress of the undamaged single-stringer panel.

Multi-stringer panels contained a stringer blade which was tapered in height. All multi-stringer panels were damaged in the skin near the tapered stiffener prior to loading to failure, and all panels failed through the impact site. Interlaminar stresses and bending strains were relatively small in the multi-stringer panels. Multi-stringer panels with damage less than a 0.11inch-deep dent failed with more stress in the skin than the design stress. The most severely damaged panel had a dent depth that was 50 percent deeper than required to define visible damage, and the panel failed with the stress at the impact site equal to approximately 10 percent less than the design stress.

Stringer terminations with a blade tapered in thickness induce high shear strains and high interlaminar stresses not seen in stringer terminations with the blade tapered in height. Impact damage to the skin of these panels does not appear to cause significantly reduced failure loads.

\section{$\underline{\text { References }}$}

1. Jegley, Dawn C. and Bush, Harold G., Structural Test Documentation and Results for the McDonnell Douglas All-Composite Wing Stub Box, NASA TM 110204, April 1997.

2. Markus, Alan, Thrash, Patrick, and Grossheim, Brian, Manufacturing Development and Requirements for Stitched/RTM Wing Structure, Proceedings of the Fourth NASA/DoD Advanced Composites Technology Conference, NASA CP 3229, 1993, pp. 503-523.

3. Brogan, F. A., Rankin, C. C., and Cabiness, H. D., "STAGS User Manual," LMSC P032594, 1994.

4. Hinrichs, Steven, General Methods for Determining Stitched Composite Material Stiffnesses and Allowable Strengths, Volume I, McDonnell Douglas Report Number MDC94K9113, March 1995.

Table 1. Damage description.

\begin{tabular}{|c|c|c|c|}
\hline Panel & Method of damage & Damage depth, in. & Damage size, in. \\
\hline \multicolumn{4}{|c|}{ Single-stringer } \\
\hline U-1 & none & - & - \\
\hline \multirow[t]{2}{*}{ U-2 } & static indentation & .155 & $3.8 \times 2.2$ \\
\hline & dropped weight (multiple impacts) & .155 & $2.0 \times 0.9$ \\
\hline \multicolumn{4}{|c|}{ Multi-stringer } \\
\hline L-1 & dropped weight (multiple impacts) & .163 & $5.2 \times 3.0$ \\
\hline $\mathrm{L}-2$ & dropped weight (multiple impacts) & .108 & $4.0 \times 2.1$ \\
\hline $\mathrm{L}-3$ & dropped weight $100 \mathrm{ft}-\mathrm{lb}$ & $\sim 0$ & $\sim 0$ \\
\hline
\end{tabular}


Table 2. Material properties.

\begin{tabular}{ccc}
\hline \hline & $\begin{array}{c}\text { Stitched AS4/3501-6 } \\
\text { (panels U-1 and U-2) }\end{array}$ & $\begin{array}{c}\text { Stitched AS4/IM7/3501-6 } \\
\text { (panels L-1, L-2, and L-3) }\end{array}$ \\
\hline Longitudinal stiffness & $8.17 \times 10^{6} \mathrm{psi}$ & $9.98 \times 10^{6} \mathrm{psi}$ \\
Transverse stiffness & $4.46 \times 10^{6} \mathrm{psi}$ & $4.45 \times 10^{6} \mathrm{psi}$ \\
Shear stiffness & $2.35 \times 10^{6} \mathrm{psi}$ & $2.57 \times 10^{6} \mathrm{psi}$ \\
Poisson's ratio & .458 & .409 \\
\hline \hline
\end{tabular}

Table 3. Summary of panel failure results.

\begin{tabular}{|c|c|c|c|c|c|c|c|}
\hline & $\begin{array}{l}\text { Failure } \\
\text { load, } \\
\text { lb }\end{array}$ & $\begin{array}{c}\text { Failure load } \\
\text { prediction } \\
\text { using PDF } \\
\text { parameter, lb }\end{array}$ & $\begin{array}{l}\text { Primary cause of } \\
\text { failure }\end{array}$ & $\begin{array}{c}\text { Design } \\
\text { stress,* } \\
\text { ksi }\end{array}$ & $\begin{array}{l}\text { Failure } \\
\text { stress at } \\
\text { impact } \\
\text { site, ksi }\end{array}$ & $\begin{array}{l}\text { Maximum } \\
\text { stress in } \\
\text { skin at } \\
\text { failure, ksi }\end{array}$ & $\begin{array}{c}\text { Load at which } \\
\text { design stress } \\
\text { occurs at impact } \\
\text { site, lb }\end{array}$ \\
\hline $\mathrm{U}-1$ & 99,200 & (no damage) & $\begin{array}{c}\text { interlaminar and } \\
\text { shear strain }\end{array}$ & 37.5 & $\begin{array}{c}\text { (no } \\
\text { damage) }\end{array}$ & 32.2 & \\
\hline $\mathrm{U}-2$ & 94,600 & 95,547 & $\begin{array}{c}\text { axial strain at impact } \\
\text { site }\end{array}$ & 37.5 & 29.4 & 29.4 & 120,500 \\
\hline L-1 & 435,000 & 640,000 & $\begin{array}{c}\text { axial strain at impact } \\
\text { site }\end{array}$ & 39.4 & 35.2 & 51.0 & 487,087 \\
\hline L-2 & 484,000 & 570,000 & $\begin{array}{c}\text { axial strain at impact } \\
\text { site }\end{array}$ & 39.4 & 44.6 & 59.6 & 428,307 \\
\hline L-3 & 610,000 & 640,000 & $\begin{array}{l}\text { axial strain at impact } \\
\text { site }\end{array}$ & 43.5 & 50.0 & 66.0 & 529,319 \\
\hline
\end{tabular}

*based on skin thickness and MDA criterion 